\title{
Humphreys mentor: "saúde" e "doença", prevenção e tratamento em um manual de medicina popular oitocentista
}

\author{
[Humphreys Mentor: "Health" and "Disease", Prevention and Treatment in a \\ 19th Century Manual of Popular Medicine]
}

\author{
André Portela do Amaral \\ (Universidade Federal de Pelotas, Brasil) \\ andreporteladoamaral@gmail.com
}

\begin{abstract}
Resumen:
Compreendendo a medicina oitocentista como um complexo e vasto campo, composto por diferentes formatos de saberes e práticas de cura, com linhas interpretativas diversas a respeito das noções de "saúde" e "doença" e das sugestões terapêuticas, propomos a análise de um modelo específico apresentado pelo homeopata estadunidense Frederick Humphreys em seu manual de medicina popular "Humphreys Mentor". Acreditamos que a reflexão em torno do conteúdo desse material e da sua circulação (levantamos indícios de uma interessante circulação na América Latina em fins do século XIX) contribui para a construção de uma compreensão mais clara de um panorama geral do período, uma vez que os debates apresentados nesse tipo de literatura e a adoção de certas estratégias no sentido de difundir as propostas de cura e prevenção, bem como, de angariar legitimação para as mesmas, parecem indicar algumas das características das trocas e disputas firmadas nesse contexto por diferentes agentes.
\end{abstract}

Palavras-chave: Manual; Medicina popular; Homeopatia; História da saúde

\begin{abstract}
:
Understanding 19th century medicine as a complex and vast field, composed of different formats of knowledge and healing practices, with different interpretative lines regarding the notions of "health" and "disease" and therapeutic suggestions, we propose the analysis of a specific model presented by the American homeopath Frederick Humphreys in his popular medicine manual "Humphreys Mentor". We believe that the reflection around the content of this material and its circulation (we raised signs of an interesting circulation in Latin America at the end of the 19th century) contributes to the construction of a clearer understanding of the general panorama of the period, since the debates in this type of literature and the adoption of certain strategies in order to disseminate the proposals for cure and prevention, as well as to obtain legitimacy for them, seem to indicate some of the characteristics of the exchanges and disputes signed in this context by different agents.
\end{abstract}

Keywords: Manual; Popular medicine; Homeopathy; Health history

Recibido: $17 / 11 / 2020$

Evaluación: 29/01/2021

Aceptado: 19/04/2021

Anuario de la Escuela de Historia Virtual - Año 12 - Nº 19 - 2021: pp. 33-46.

ISSN: 1853-7049

http://revistas.unc.edu.ar/index.php/anuariohistoria 


\section{Humphreys mentor: "saúde" e "doença", prevenção e tratamento em um manual de medicina popular oitocentista}

$\mathrm{A}$

o desenvolvermos uma reflexão sobre o campo dos saberes e práticas de cura do oitocentos encontramos indícios de um panorama complexo e diversificado, com diversos atores e propostas terapêuticas existentes. Diferentemente do que indicava uma produção historiográfica mais tradicional, que dava conta de um quadro fechado, homogêneo e de predominância da medicina ortodoxa, ao longo das últimas décadas temos a insurgência de estudos que evidenciam uma enorme variedade de formatos no período. Atendo-nos apenas à historiografia brasileira, podem ser destacados importantes trabalhos como os de Chalhoub (1996), Weber (1997), Pimenta (1997), Sigolo (1999), Edler (1999), Guimarães (2003), Figueiredo (2005), Luz (2014), entre outros, que têm trazido reflexões fundamentais para a composição de um quadro histórico diversificado de saberes, práticas e agentes de cura no período em questão.

A busca e a reconsideração de uma variedade de fontes documentais vêm possibilitando importantes redescobertas -acentuando a coexistência de diferentes modelos interpretativos da saúde e da doença (diversas vezes conflituosos), que tiveram uma dimensão prática marcada pela presença de múltiplos agentes atuando em diversos espaços e por meio de determinadas estratégias-. Dentre essa enorme diversidade de saberes e práticas que compuseram um quadro geral do campo médico no oitocentos, temos a homeopatia -sistema médico desenvolvido na Europa por Samuel Hahnemann na passagem do século XVIII para o XIX, que se expandiu mundialmente, inclusive para a América Latina e o Brasil, em algumas décadas-. A introdução e a expansão da homeopatia foram marcadas por uma relação tumultuada com a medicina alopática, pela existência de trocas com outros formatos "populares" de cura (essas ainda pouco exploradas pela maioria dos estudos) e, mesmo, por divergências internas.

Nessa linha, partindo de um modelo de cura específico dentro do campo homeopático, procuramos trazer uma breve reflexão a respeito de algumas particularidades de um sistema de saberes e práticas médicas que no século XIX se apresentava como modelo racional e científico concorrencial à medicina tradicional, apresentando uma alternativa não só para a prática terapêutica, mas também para as próprias formas de compreensão do fenômeno saúde-doença. Desse modo, sugerimos a existência de um campo médico bastante diversificado no período e com fronteiras entre os diferentes formatos bem menos rígidas do que se convencionou considerar.

As disputas seguidas pelo desenvolvimento da homeopatia não se deram apenas de forma externa, mas também se revelaram no âmbito interno. A diversificação de 
correntes interpretativas sobre os fundamentos da doutrina de Hahnemann, com o passar dos anos, impulsionou acalorados debates sobre a terapêutica homeopática. Além disso, as diferenças políticas e os interesses diversificados dos grupos marcaram alianças e disputas em torno das instituições homeopáticas e da definição das estratégias de expansão da homeopatia. A produção de manuais de medicina popular vinculados à homeopatia (e mais especificamente a uma determinada corrente dentro do campo) é demonstrativa de um tipo de estratégia e da difusão de um formato específico dentre os diferentes modelos de medicina propostos no período.

Figueiredo (2005) comenta como a produção de "guias" ou "manuais de saúde popular", ao longo do século XIX, teria servido, de modo estratégico, para uma iniciativa de inserção de um tipo de conhecimento -ligado ao espaço acadêmico- para um público ampliado e composto, de modo significativo, por leigos em medicina. Beatriz Weber (2005), olhando para o caso da inserção da homeopatia no estado do Rio Grande do Sul (sul do Brasil), também observa o uso dos manuais como elemento estratégico na ampliação de público. O convencimento e a legitimação eram buscados pelos homeopatas através da utilização da linguagem simplificada e do discurso de sugestão dos conhecimentos propostos como legítimos modelos do "saber científico" da época. Esses materiais não só incorporavam diversas vezes elementos já bastante difundidos pela terapêutica popular, como eram também apropriados e ressignificados por diferentes agentes populares de cura.

A verificação do formato dos textos de manuais de medicina popular e da existência de uma considerável circulação desse tipo de literatura médica em fins do oitocentos nos ajuda a entender algumas das estratégias adotadas por um determinado grupo, no sentido de ampliar sua presença dentro das esferas de debate sobre a saúde e o desenvolvimento de políticas em torno dela mesma. Além da produção local de uma literatura médica, a exemplo da confecção de manuais de medicina popular pelo homeopata Visconde de Souza Soares (1846-1911), na cidade de Pelotas (RS) no sul do Brasil, temos indícios de uma interessante entrada de literatura estrangeira não apenas no Brasil, mas possivelmente nos países vizinhos. Investigamos especificamente a introdução das publicações de Frederik K. Humphreys -homeopata estadunidense, cujas obras tiveram inserção internacional bastante significativa-.

Palma (2019), em estudo sobre os primórdios da homeopatia no Peru, identifica a existência de uma via de entrada da nova proposta de terapia médica naquele país através dos Estados Unidos, na década de 1890, com o estabelecimento do homeopata George Deacon. Conforme comenta, apesar de a homeopatia ter se inserido dentro de um espaço disputado por diversas outras práticas terapêuticas, a "nova medicina" teria conseguido atrair um expressivo esforço repulsivo advindo da corporação médica ortodoxa (encarnada pela Faculdade de Medicina de Lima -que detinha o monopólio sobre a formação médica e a regulamentação das práticas), especialmente pelo formato 
de algumas das suas estratégias de inserção (vinculadas à atuação política de Deacon), chegando a ser encarada uma ameaça ao monopólio da medicina regular-.

No entanto, os esforços da medicina ortodoxa aparentemente se concentravam em coibir a formação de instituições homeopáticas e a própria atuação prática dos homeopatas (com a restrição aos títulos profissionais e a caçada contra a "prática ilegal da medicina"), sendo que, um outro elemento estratégico apontado -considerado pela autora como o verdadeiro "cavalo de Troia" da homeopatia no país- teria sido praticamente ignorado e sofrido poucos ataques: a inserção da literatura e dos kits de medicamentos homeopáticos estrangeiros, que tinham um papel importante para a popularização da prática, sobretudo em regiões do interior e entre os leigos em medicina.

Enquanto isso, uma considerável venda e circulação de produtos homeopáticos em território peruano contribuía para a penetração da homeopatia em espaços onde a figura do médico ainda era escassa. Os manuais de instrução e as caixas de medicamentos facilitavam o exercício da "medicina doméstica", através de um formato de "popularização" da prática médica que não deixava, entretanto, de se sustentar discursivamente como um legítimo modelo de saber científico. Dentre os produtos citados, se destacavam aqueles produzidos pela Humphreys Homeopathic Medicine Co., que em 1890 publicara versões dos manuais médicos instrutivos do Dr. Humphreys em diversos idiomas, incluindo o espanhol e o português.

Como aponta Luz (2014), no Brasil também tivemos um ambiente de acirrada disputa entre a homeopatia e a alopatia, que inclusive ajudou a moldar as estratégias em torno da busca por expansão e institucionalização homeopática durante o século XIX. Entretanto, para além disso, é perceptível a coexistência de diferentes grupos e formatos dentre os próprios homeopatas, com diferenças relacionadas às estratégias, ao método terapêutico e aos limites de concessão e diálogo com a alopatia. A observação da inserção de uma literatura estrangeira como a de Humphreys pode nos ajudar a traçar algumas hipóteses sobre a forma com que eram conduzidos, incorporados e ressignificados alguns debates entre esses grupos.

A partir da constatação da existência de um número expressivo de anúncios publicitários dos produtos de Humphreys (medicamentos, kits homeopáticos e literatura) em jornais de todo o Brasil, sugerimos a possível existência de uma interessante circulação deles no país. Realizando uma busca em periódicos na plataforma online da Biblioteca Nacional para a década de 1890, verificamos a incidência de anúncios promovendo o tratamento curativo do Dr. Humphreys e propagandeando os benefícios da compra do livro e dos medicamentos.

Utilizando a palavra-chave "humphreys", mapeamos anúncios dos produtos nas regiões Norte, Nordeste, Sudeste e Sul, sendo o maior número deles nas duas últimas regiões citadas. Foram verificadas ocorrências nos seguintes estados: Amazonas, Alagoas, Bahia, Ceará, Espírito Santo, Maranhão, Minas Gerais, Pará, Paraíba, Pernambuco, Paraná, Rio Grande do Sul, Santa Catarina e São Paulo. A título de exemplo, somente no estado do Rio Grande do Sul foram encontradas 176 ocorrências, 
em 7 dos 63 periódicos disponíveis para acesso na plataforma ("A Federação", "Almanak Litterario e Estatistico", "Correio Mercantil”, "Folha do Sul”, "Rio-Grande”, "Almanach Popular Brazileiro" e "O Rio-Grande").

Em trecho retirado de um anúncio de 1890, promovido pela Pharmacia Central de José Francisco de Moura, no periódico O Estado da Parahyba, temos uma ideia do conteúdo presente em chamadas publicitárias em diferentes regiões do país sobre a disponibilidade dos produtos de Humphreys. Optamos por manter a grafia original das fontes.

É uma realidade conhecida o efeito prompto dos Específicos Homeopathicos do Dr. Humphreys. [...] As carteiras completas são acompanhadas de um grande manual em rica encadernação. Vende-se separadamente também o mesmo livro, e da-se gratuitamente pequenos manuaes que ensinão o tratamento das moléstias [...] Sucesso já conhecido [...]. (O Estado da Parahyba, 1890, p. 4).

Como pudemos perceber ao consultar os anúncios em periódicos, os produtos distribuídos por Humphreys aparecem de modo mais significativo a partir da década de 1890, especialmente nos últimos anos daquele século. Esse incremento nos anúncios acompanhou o lançamento da versão em língua portuguesa do manual Mentor do Dr. Humphreys, antes disso (e em menor escala) apareciam propagandas da chamada "maravilha curativa" do Dr. Humphreys: um fitoterápico indicado para múltiplos tratamentos. A maior concentração dos anúncios encontrados é na região sudeste, mas acreditamos que isso não necessariamente significa que outras regiões nas quais encontramos menor incidência em nossas pesquisas tivessem de fato pouca circulação, talvez uma busca em outras bases pudesse trazer diferentes resultados.

O fato do manual ter sido produzido nos Estados Unidos, por um homeopata estadunidense, diz muito sobre alguns dos debates presentes na obra, relacionados ao contexto espacial e temporal em que foram desenvolvidos. Por isso, faz-se necessário considerar o campo médico e as disputas dentro e fora da homeopatia nos Estados Unidos no período. Contudo, lembramos que no momento de publicação da obra, o autor já contava com uma expressiva inserção internacional de seus textos, dedicando inclusive algumas passagens para a consideração de temas e características de diferentes regiões do planeta: como a Europa, a Índia e o Brasil. Outrossim, pensamos inicialmente na utilização desse documento por considerarmos interessante pensar a circulação expressiva de um material estrangeiro no Brasil. 


\section{Os específicos e o manual do Dr. Humphreys}

Frederick K. Humphreys (1816-1900), estadunidense com formação médicohomeopática, desenvolveu a partir de meados do século XIX um formato terapêutico ancorado na produção dos chamados "específicos homeopáticos". Baseado na doutrina de Samuel Hahnemann, ele defendia a cura pelos semelhantes (chamada por ele de "medicina substitutiva") e as doses ultra diluídas na composição de medicinas. Entretanto, a despeito das críticas oriundas de grupos mais apegados aos princípios clássicos do sistema hahnemanniano, propunha alguns rompimentos e o que considerava como avanços na terapêutica homeopática, a fim de, segundo ele, facilitar a prática e ampliar o sucesso no emprego dos medicamentos.

Como mencionado, apesar de manter o princípio da similia e das doses infinitesimais, Humphreys admitia a alternação de diferentes medicinas, constituídas pela combinação de diferentes substâncias. Além disso, apresentava seus específicos numericamente (sem a especificação de sua composição), e, por mais que alegasse respeitar a individualidade do paciente como requisito para a prescrição dos medicamentos (um princípio bastante caro para a homeopatia hahnemanniana), trazia na literatura instrutiva e auxiliar muito mais uma observação geral de características sintomáticas comuns, de acordo com um determinado repertório de doenças e uma dosagem igualmente generalista. Tais aspectos do modelo de cura proposto por Humphreys renderam algumas animosidades que podem ser notadas no próprio tom discursivo adotado pelo autor em seu livro "Mentor", marcado pela insistência da afirmação da legitimidade de suas propostas e pela defesa contraprováveis críticas advindas de diferentes grupos (fossem praticantes da homeopatia ou da alopatia).

A crítica em relação a uma linha da homeopatia que se mantinha apegada ao princípio da dose única, era levantada pela consideração de que se fazia necessário reconhecer que a "regra da cura era mais larga" do que se imaginava. Essa ideia abria espaço para o autor apresentar seu método terapêutico -defendido como sinônimo de "progresso" (um avanço dentro da terapêutica homeopática, pela facilitação do preparo e do uso, bem como, pela potencialização dos resultados)-. Além de tudo, Humphreys rebatia os questionamentos sobre a eficácia das medicinas específicas e as possíveis atribuições dos resultados positivos de seu tratamento ao "placebo" (críticas provavelmente advindas da alopatia, que considerava absurdo o emprego das doses ultra diluídas). Ainda, (re)afirmava a singularidade de seu método de cura, sendo esse defendido como vantajoso não apenas pela simplicidade de sua aplicação na prática, mas também, pela garantia dos resultados -em especial no tratamento de doenças crônicas, que demandaria mais tempo-. 
Tendo se formado no Homeopathic Medical College of Pennsylvania, onde recebeu orientações de Constantine Hering, ${ }^{1}$ Humphreys transitou em importantes círculos e foi membro de algumas das principais instituições homeopáticas estadunidenses em meados do século XIX. Ajudou a fundar a The Central New York Homeopathic Medical Society, ocupou um cargo de liderança no American Institute of Homeopathy e foi docente por três anos na mesma instituição em que obteve sua formação. No entanto, ao iniciar uma difusão mais sistemática dos resultados de seus estudos, traduzidos num método de cura particular, Humphreys acabou rompendo com o grupo de homeopatas vinculados a esse núcleo institucional.

Em 1854 fundou a Humphreys' Specific Homeopathic Medicine Co., passando a produzir e comercializar seus específicos homeopáticos para diversas partes do mundo. Como estratégia de divulgação do método terapêutico e dos seus produtos, confeccionou uma literatura auxiliar que servia também como um "guia prático" para o exercício da medicina homeopática no âmbito doméstico. Os textos escritos em linguagem acessível e com apresentação dos temas de modo simplificado tinham como objetivo atingir um público amplo, composto especialmente por indivíduos leigos em medicina. Dentre os textos publicados por Humphreys destacamos o livro Humphreys Mentor, lançado originalmente em 1873 em língua inglesa, e em 1890 tendo sua publicação em língua espanhola e portuguesa -no último caso sob o título "Mentor do Dr. Humphreys ou Conselheiro da Família para o uso da medicina específica" (versão na qual baseamos nossa análise)-.

Trazemos um trecho do prefácio do autor: "como esta obra é designada para o uso do Povo, os pontos mais manifestos devião ser sua completa adaptação aos seus requerimentos. Deverá ceder tal conselho como possam necessitar na sua procura, não somente para a recuperação de saúde perdida, porêm para a preservação e o melhoramento da mesma" (Humphreys, 1890, p. III). O livro em questão é um exemplar da produção de um tipo de literatura médica da segunda metade do século XIX, caracterizado enquanto "manual prático de saúde". Contendo quase quinhentas páginas, apresentava uma divisão estrutural que privilegiava a exposição do olhar particular do autor a respeito da saúde e da doença, com considerações sobre características de diversas moléstias e suas manifestações sintomáticas mais comuns, além da apresentação de recomendações de tratamento e prevenção das mesmas (essencialmente pelo uso das medicinas específicas aliadas ao cumprimento das normativas higiênicas prescritas pelo médico).

O manual era comercializado separadamente ou em conjunto aos específicos homeopáticos do Dr. Humphreys. No caso da aquisição de caixas contendo os medicamentos -as chamadas “boticas da família”- o Mentor era entregue conjuntamente

\footnotetext{
${ }^{1}$ Conhecido como "pai da homeopatia estadunidense", Hering foi o mais influente homeopata daquele país durante a primeira metade do oitocentos. Nasceu na Saxônia e migrou para os Estados Unidos, onde ajudou a fundar diversas instituições homeopáticas, incluindo a Allentown Academy, em 1835 -a primeira escola de formação homeopática do mundo e o germe do futuro Medical College of Pennsylvania (Schmidt, 1998)-.
} 
e sem custos adicionais. ${ }^{2}$ As boticas eram compostas por frascos de vidro com os medicamentos específicos (pequenas "bolinhas"), esses envoltos por um papel indicando seu número e recomendação. As caixas variavam em tamanho, material de construção e quantidade de frascos de medicamentos em seu interior. Podemos ter uma noção das características das boticas a partir da observação de um trecho presente no livro, onde era detalhada a configuração da botica de número 1: "Com 35 Frascos de TrezDrachmas, CAIXA DE NOGUEIRA PRETA, ENVERNIZADA, forrada de velludo de seda purpura, enfeites de nickel, e fechadura com chave; contém os 35 Especificos e o MENTOR DO DR. HUMPHREYS (474 páginas), encadernação de panno e com o retrato do autor." (Humphreys, 1890, p. 464, grifo do autor).

O Mentor do Dr. Humphreys trazia de modo geral sugestões de tratamento e prevenção ancoradas no uso dos específicos e do cuidado com os hábitos relacionados à higiene individual e dos espaços coletivos. As recomendações de uso de determinado medicamento e dosagem, da dieta "correta", das práticas domésticas e dos hábitos "adequados", surgiam em meio à descrição de um repertório de doenças de "A à Z" subdivididas de acordo com categorias ("moléstias da via urinária" ou "do aparelho respiratório", por exemplo)-. Após a apresentação das características gerais da moléstia, eram citadas as principais manifestações sintomáticas da doença sobre o enfermo, e, finalmente, ações que serviriam para a recuperação do paciente e para a prevenção contra eventuais reincidências. Trazemos como exemplo a apresentação da "febre tifo"3 no manual:

A Febre Typho é definida como uma forma aguda especifica de febre, excessivamente contagiosa e infecciosa, continuando de quatorze á vinte e um dias. [...] SYMPTOMAS - O estado precursor varia; porêm [...] o paciente é muitas vezes atacado com um calefrio ou rigor, usualmente succedido por quentura secca da pelle, sede, pulso accelerado, lingua esbranquiçada, secca é ás vezes tremulosa, ourina escassa e muito corada, ás vezes vomitos, olhar pesado ou esturpor, prostação da força, e dôres musculares [...] CAUSAS Casas demasiadamente populadas, com defectiva ventilação. É muitas vezes o açoute dos pobres nas cidades grandes; [...] Privação, penuria pelas faltas das colheitas, pobreza commercial, greves e opressões, todas tendem a deteriorar a constituição e predispôr ao typho. Moradias sujas, roupa porca, e soridez pessoal. TRATAMENTO - Os ESPECIFICOS No. Um e No. Quatorze [...] Dissolve-se doze ou mais pílulas [...] em seis colheradas grandes de agua pura, da qual dê-se uma colherada cada duas horas. [...] MEDIDAS ACESSORIAS - [...] quarto grande e bem ventilado [...] mudanças da roupa

\footnotetext{
2 Exceto em modelos menores das caixas, em que a literatura auxiliar era um manual reduzido de 144 páginas (o qual se oferecia gratuitamente também de forma avulsa, como pudemos perceber nas buscas por anúncios dos produtos de Humphreys em periódicos brasileiros do período).

${ }^{3}$ Como aponta Beatriz Weber (2006), o "tifo" era uma doença bastante comum no século XIX, e, apesar da existência de diferentes interpretações sobre sua natureza no período, era de modo geral interpretada como endêmica e contagiosa. Sua presença em regiões do Brasil foi discutida e interpretada de diferentes maneiras, sendo muitas vezes associada ou confundida com outros tipos de "febre".
} 
pessôal e da cama, e da postura do paciente, para prevenir congestão e as excoriações da cama. Alimentos e bebidas devem ser dadas frequentemente e em pequenas quantidades á intervalos regulares, incluindo agua, leite [...] caldo, e chá de carne. (Ibid., p. 147, grifo do autor).

A difusão de manuais de medicina popular parece ter sido entendida por Humphreys não apenas como elemento estratégico de divulgação do seu método de cura, mas também como uma interessante ferramenta na busca de legitimação para sua proposta, uma vez que a alegação da "novidade" de seu método terapêutico residia justamente na suposta simplificação da prática. A aquisição dos específicos e do manual permitiria então que qualquer indivíduo "minimamente inteligente" tivesse à mão e pudesse fazer uso do tratamento homeopático contra uma série de enfermidades. A apresentação didática do correto uso dos específicos e a recomendação das medidas higiênicas auxiliares favoreceriam a prática da medicina doméstica, dando certa autonomia ao paciente e/ou ao cuidador. Entretanto, vale destacar que Humphreys insistia ao mesmo tempo na necessidade de uma atenção e obediência às recomendações do médico, sendo a prescrição e qualquer mudança no tratamento consideradas competências exclusivas do profissional.

Se um médico está tratando, é seu myster prescrever e não o dos outros, é um negócio muito delicado, sob quaesquer circumstancias, aconselhar o uso de uma medicina ou uma mudança de tratamento ou de médico. Em quanto um médico está encarregado do tratamento, em simples justiça para o mesmo, e o bem-estar do doente, requerem que suas direcções sejão seguidas, e suas instrucções obedecidas (Humphreys, 1890, p. 119).

Para entendermos o modelo de cura e prevenção apresentado por Humphreys em seu manual de medicina, precisamos antes de tudo refletir a respeito da forma com que o autor via a saúde e a doença. Influenciado pelo vitalismo, corrente bastante difundida no século XIX, Humphreys acreditava que a chave para a compreensão da saúde e do seu abalo, manifestado através dos sintomas patológicos, residia na captura da existência de uma natureza imaterial regendo os organismos. Os planos imaterial e material estariam interligados e necessitariam de um "equilíbrio", o contrário (desequilíbrio -que poderia ter diversas causas-) resultaria no adoecimento dos indivíduos. Na maioria das vezes o próprio organismo, chamado de "laboratório químico vital" pelo autor, seria capaz de se autorregular e garantir um retorno desse necessário equilíbrio. No entanto, em alguns casos seria preciso intervir, a fim de trazer auxílio nesse processo e evitar um esgotamento, que poderia em últimos casos resultar no falecimento do organismo.

A manifestação sintomática das doenças, que nada mais séria do que a expressão material e visível do abalo no equilíbrio vital, teria uma tendência de aparecimento de modo sequencial: partindo do "plano superior" (imaterial) até chegar na esfera material ou sensorial. Usualmente seriam percebidas alterações no humor, seguidas por sintomas 
como dor física, cansaço e falta de apetite, que seguiriam até o surgimento de sinais ou lesões cutâneas. A observação dessas manifestações seria essencial para o diagnóstico mais preciso, permitindo compreender o caráter da moléstia a ser tratada, seu estágio, e o modo mais adequado de empregar as medicinas e aplicar as medidas curativas auxiliares (vinculadas à higiene).

A lei dos semelhantes e o emprego de dosagem mínima eram defendidos por meio de uma apreciação sobre a forma com que esse "auxílio" deveria ser adotado. A cura não seria resultado de grandes quantidades de medicamento, mas apenas de uma quantidade mínima absorvida pelo organismo e suficiente para ativar uma autorregulação. O princípio de cura se dava então através do uso de doses infinitesimais de substâncias que tivessem a capacidade de gerar artificialmente os mesmos sintomas da doença que se pretendia combater. Além disso, o autor alegava que, justamente por fazer uso de uma pequena porção do princípio ativo, tais medicinas apenas podiam trazer benefícios para a saúde e se afastariam da possibilidade de causar malefícios em caso de algum equívoco na sua ingestão.

Todas as medicinas cruas são, em sua natureza, venenos ou agencias de perturbações para saúde. Em virtude de sua capacidade para arruinar a saúde, têm sob certas circumstancias o poder para restaural-a. Porêm não é necessário, com o fim de restabelecer a saúde, que as medicinas sejam usadas em quantidades suficientes á perturbar ou destruil-a." (Humphreys, 1890, p. 17).

Outro ponto bastante marcante era a percepção da existência de uma certa influência capaz de injuriar a saúde: o miasma, apresentado por Humphreys como uma agência causadora de doenças. Emanações invisíveis, carregadas pelos ares e apenas passíveis de detecção pelo olfato, os miasmas não tinham sua natureza claramente explicada, mas eram essencialmente associados aos ambientes considerados sujos e insalubres. As proximidades de pântanos, esgotos, hospitais e cemitérios, sem contar as residências mal planejadas e aqueles pontos da cidade em que viviam grandes contingentes populacionais, seriam os lugares mais propícios para a proliferação do miasma e para o surgimento de doenças.

Ao tratar das doenças, Humphreys dava destaque para "causas epidêmicas" percepção que precisa ser lida no seu contexto-. A partir de uma associação com a teoria apresentada por Sydenham (1624-1689) sobre a "constituição epidêmica" das doenças: uma natureza mórbida determinada por causas socioambientais (a desarmonia entre os seres e o espaço), podemos traçar alguns aspectos que predominavam na leitura de Humphreys sobre a saúde e a doença (Czeresnia, 2001). Numa configuração neohipocrática, seu modelo considerava as mudanças climáticas e das condições da atmosfera, o "envenenamento" pela exposição aos ares carregados de "miasma pestilencial" ou pela água contaminada, e as práticas "pouco saudáveis" (como a má- 
alimentação e os vícios, por exemplo), como questões bastante determinantes para o acometimento por doenças. A dieta, os hábitos e os cuidados com a higiene do corpo e dos espaços de moradia/trabalho/convivência se tornavam assim alvos diretos de intervenção na proposta de cura e prevenção do estadunidense.

Definidas como "medidas acessórias curativas", algumas terapias eram recomendadas como práticas aliadas do tratamento médico. Adotadas pelo paciente e pelo cuidador, tais medidas ajudariam no alívio de sintomas da ação mórbida e acelerariam o processo de cura. Podendo ser administradas na prática doméstica, eram apresentadas sob a forma de banhos mornos (imersão, vapor, "escalda pés"), fomentações (molhadas e secas), injeções (de água morna e/ou com sal, através do reto) e inalação (vapor), etc. $\mathrm{O}$ autor apresentava tais medidas de modo bastante detalhado, sugerindo a utilização de utensílios domésticos e de adaptações simples que possibilitariam seu fácil emprego. Além do método, também era prescrita a frequência aconselhada.

Uma pessôa pode ser extemporisada, amarrando um tubo sobre o esguicho da chaleira, segurando á outra ponta n'um pequeno cesto, debaixo d'uma cadeira, assento de palha; o paciente se senta na cadeira, sendo coberto, bem como a cadeira por dous cobertores, seguros á roda do pescoço e pela frente até o chão. Durante o banho, se poderá beber um ou dous copos de agua fria; e a dôr de cabeça se estiver presente, pode ser aliviada esponjando com agua fria, ou por meio d'um panno com agua fria á roda da cabeça. Depois de transpirar por 10 ou 15 minutos, o paciente deve ser promptamente enxugado e posta na cama (Ibid., pp. 121-122).

A recomendação da dieta do doente, de modo geral, passava mais pelo cuidado de evitar a ingestão de alimentos e bebidas com capacidade de irritar o organismo e causar indigestão. Era sugerido o consumo de alimentos digestivos e nutritivos, com observação às particularidades do doente (natureza da moléstia em tratamento, estágio da doença, tipo físico/faixa etária/gênero do paciente, por exemplo). Além disso era bastante destacada a importância de isolar o enfermo e de cuidar para que o quarto e os objetos em contato com ele fossem devidamente higienizados: isso não se dava necessariamente pela compreensão de um caráter contagioso para as doenças, mas substancialmente pela percepção de que o doente também poderia ser fonte de emanação de miasmas.

A localização das moradias e dos espaços de trabalho, suas características físicas, a limpeza e a conservação desses ambientes também eram questões das quais Humphreys desprendia atenção. Partindo de uma premissa sobre a importância da adequada iluminação solar e da circulação de ar puro e fresco para a preservação de uma vida saudável, Humphreys trazia vários comentários a respeito do que seriam "condições ideais" para os espaços, e quais as medidas importantes a serem tomadas para garantir 
sua salubridade. Observava que problemas comuns nesse sentido, contribuíam para a deterioração das energias vitais e intensificavam os riscos de adoecimento.

O ponto especial para uma residencia sadia deve ser absolutamente falta de humidade; particularmente nos alicerces e cumieira. O lugar deve ser secco, de onde pode correr a água; e, se não sobre um desfiladeiro natural, o escoamento artificial deve ser perfeito. $\mathrm{O}$ aspecto deve ser meridional; e o vento deve ter livre acceso em cada lado. Os quartos de dormir devem, se possível, confrontar o sol. [...] Se na cidade, a casa deve olhar para um parque, largo, ou outro lugar aberto, ou ao menos em uma rua larga e arejada, com um aspecto favorável. (Humphreys, 1890, pp. 102-103).

A vinculação da manifestação das doenças aos hábitos dos pacientes, dava abertura para as recomendações higienistas e o destacado regramento comportamental, expressos por meio de códigos de conduta para a higiene corporal, para as questões do trato social e os cuidados com o ambiente-salubridade, ventilação, iluminação). Os "desvios" eram ligados diretamente à doença, a perda da saúde seria então resultante das "violações" cometidas pelos indivíduos ou comunidades.

Quando um indivíduo ou communidade têm por um longo período violado as leis da vida ou saúde, a violação parece ultimar-se na forma de uma moléstia particular correspondente, que tendo uma vez manifestado-se nessa forma particular, assume um typo, e d'ahai, constantemente tende á reproduzir-se em novos assumptos. (Humphreys, 1890, p. 15).

\section{Considerações}

A verificação da circulação de manuais de medicina popular durante a segunda metade do século XIX no Brasil nos ajuda a traçar algumas hipóteses sobre a existência de um intercâmbio de ideias e a incorporação de debates internacionais -introduzidos e ressignificados de acordo com interesses e particularidades locais-. O modelo terapêutico sugerido pelo homeopata estadunidense deve ser conectado ao seu contexto, para que assim possamos compreender também como tal literatura foi apropriada e (re) por diferentes grupos e agentes, num ambiente de transformações políticas, sociais e econômicas, de intensos debates e diversas disputas entre diferentes propostas de pensar e agir sobre a "saúde" e a "doença", com rupturas e tensionamentos também delimitados pela constante ameaça epidêmica.

Durante boa parte do século XIX prevaleceu um reconhecimento das condições ambientais, aliadas ao regime alimentar e de bebidas, como fatores essenciais para $\mathrm{o}$ adoecimento e como principais alvos de intervenção nos diferentes modelos que buscavam cura e prevenção. Uma base neo-hipocrática dava abertura para discussões 
em torno das supostas causas miasmáticas das moléstias, abraçadas por homeopatas e alopatas -que geralmente concordavam sobre a importância da higiene e da limpeza como ferramenta de destruição dos elementos de infecção miasmática-. Apesar de termos focado na interpretação de Humphreys sobre a "saúde" e a "doença", atravessando sua percepção sobre questões como a "influência miasmática", vale ressaltar que a teoria miasmática predominava no período e era utilizada como uma perspectiva biológica que ajudava diferentes correntes a explicar a causa etiológica para o adoecimento, bem como, orientar ações no sentido da cura e da prevenção.

Diferente de existirem formatos homogêneos, ao que parece, conviviam (nem sempre de modo pacífico) agentes e práticas diversificadas, que disputavam espaço e buscavam se inserir/conquistar legitimidade e adeptos a partir de estratégias próprias. Dentro da própria homeopatia havia diferenças na leitura das estratégias a serem adotadas, sobre a terapêutica e sobre a interpretação da doutrina hahnemanniana. A produção de manuais de medicina popular representava um dos formatos estratégicos do período. $\mathrm{O}$ modelo terapêutico proposto por Humphreys é apenas um exemplar da existência de um vasto campo de saberes e práticas.

Assim como a medicina ortodoxa, a homeopatia se apresentava como representante de um saber legítimo e científico, uma "vontade de verdade" expressa a partir da apropriação de signos e do discurso, que se ancorava na construção de um regime de verdade e na proclamação de um saber enquanto legítimo (por meio de diferentes estratégias). No manual observado, a afirmação de uma base científica legitimadora das recomendações de tratamento e prevenção apresentadas é recorrente. A definição do "correto" e do "saudável", em detrimento de outras práticas condenadas, evidencia um exercício de poder e a busca pela legitimação de determinados interesses.

\section{Referencias bibliográficas}

(Edição 00076 (1). de 1890). O Estado da Parahyba: Periodico Politico Social e Noticioso Orgão Republicano (PB).

Chalhoub, S. (1996). Cidade febril: cortiços e epidemias na Corte imperial. São Paulo: Cia das Letras.

Czeresnia, D. (2001). Constituição epidêmica: velho e novo nas teorias e práticas da epidemiologia. História, Ciências, Saúde-Manguinhos, 8 (2), 341-56.

Edler, F. C. (1999). A constituição da Medicina Tropical no Brasil oitocentista: da climatologia à parasitologia médica. Tese de Doutorado. Rio de Janeiro: UERJ.

Figueiredo, B. G. (2005). Os manuais de medicina e a circulação do saber no século XIX no Brasil: mediação entre o saber acadêmico e o saber popular. Educar, 25, 59-73.

Foucault, M. (1998). Microfísica do Poder. Rio de Janeiro: Graal. 
Guimarães, M. (2003). Civilizando as Artes de Curar: Chernoviz e os Manuais de Medicina Popular do Império. Dissertação de Mestrado. Rio de Janeiro: FIOCRUZ.

Humphreys, F. (1890). Mentor do Dr. Humphreys ou Conselheiro da Família para uso da medicina específica.

Luz, M. T. (2014). A arte de curar versus a ciência das doenças: História social da homeopatia no Brasil. (2 $2^{\underline{a}}$ ed.). Porto Alegre: Rede Unida.

Palma, P. (2019). George Deacon and the circulation of homeopathic therapies in Lima (1880-1915). História, Ciências, Saúde-Manguinhos, 26(4), 8-10.

Pimenta, T. S. (1997). Artes de curar: um estudo a partir dos documentos da Fisicatura-mor no Brasil do começo do século XIX. Dissertação (mestrado). Campinas: Unicamp.

Pimenta, T. S. (2004). Doses infinitesimais contra a epidemia do cólera em 1855. Em D. R. Nascimento y D. M. Carvalho (Eds.), Uma história brasileira das doenças. Brasília: Paralelo 15.

Sigolo, R. P. (1999). Em busca da "Sciencia Medica": a medicina homeopática no início do século $X X$. Tese (Doutorado). Curitiba: UFPR.

Weber, B. T. (1997). As artes de curar: medicina, religião, magia e positivismo na República RioGrandense, 1889-1928. Tese (doutorado). Campinas: Unicamp.

Weber, B. T. (2005). Como convencer e curar: a introdução da homeopatia no Rio Grande do Sul. XXIII Simpósio Nacional de História. Londrina: ANPUH.

Para citar este artículo:

Portela do Amaral, André (2021). Humphreys mentor: "saúde" e "doença", prevenção e tratamento em um manual de medicina popular oitocentista. Anuario de la Escuela de Historia Virtual, 19, 33-46. 